\title{
Effect of Chemotherapy and Hormonal Therapy on Bone Mineral Density in Patients with Breast Cancer in Saiful Anwar Hospital Malang
}

Ade Nurshanty ${ }^{1}$, Shinta O Wardhani ${ }^{2}$ BP Putra Suryana ${ }^{2}$

${ }^{1}$ Specialist Doctor-I Education of Internal Medicine, Faculty of Medicine, Universitas Brawijaya, dr. Saiful Anwar, General Hospital, Malang.

2 Division of Hematology and Medical Oncology, Department of Internal Medicine, Faculty of Medicine, Universitas Brawijaya, dr. Saiful Anwar General Hospital, Malang.

${ }^{3}$ Rheumatology Consultant, Division of Rheumatology, Department of Internal Medicine, Faculty of Medicine, Universitas Brawijaya, dr. Saiful Anwar General Hospital, Malang.

\section{A R T I C L E I N F O}

Corresponding Author:

Shinta O. Wardhani

Division of Hematology and Medical

Oncology, Department of Internal

Medicine, Faculty of Medicine,

Universitas Brawijaya, Dr. Saiful Anwar,

General Hospital, Malang.

Email: Shinta-oktya@ub.ac.id

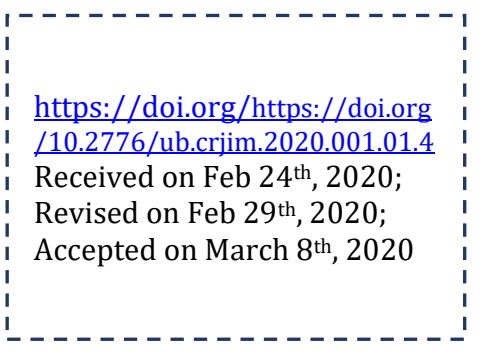

A B S T R A C T

\begin{abstract}
Osteoporosis is an important health problem, and the number of patients who suffered from it is increasing. Breast cancer is a condition that has a high risk of osteoporosis. Cancer induced bone disease results from the primary disease, metastatic process, or from therapies against the prime condition, causing bone fragility. Therefore, there are still different opinions regarding the therapeutic effect of breast cancer on bone mineral density. Aim: to determine the effect of chemotherapy and hormonal therapy on bone mineral density in patients with breast cancer in Saiful Anwar Hospital Malang. Method: this is a case-control study conducted in 30 patients with breast cancer who had undergone chemotherapy and hormonal therapy are compared to 30 patients without breast cancer as controls. Bone Mineral Density (BMD) was measured by DEXA. Result: there are $53 \%$ of breast carcinoma patients having osteopenia and 13\% having osteoporosis, with one patient has osteoporosis located in the femoral neck and three patients in lumbar $(\mathrm{L} 1-\mathrm{L} 4)$. We obtain a significant T-score $(\mathrm{p}=0.02)$ in the great trochanter. Odds Ratio (OR) 0.233 with $p=0.008$ showed a protective effect of chemotherapy and hormonal therapy for breast cancer to the bone density. Conclusion: the incidence of osteoporosis in the study was $13 \%$, with the most location in the lumbar spine. Chemotherapy and hormonal therapy had a protective effect on BMD in patients with breast cancer in Saiful Anwar Hospital Malang.
\end{abstract}

Keywords: breast cancer, bone mineral density hormonal therapy, osteoporosis

\section{N T R O D U C T I O N}

Osteoporosis or porous bone is a disorder characterized by increased skeletal fragility as a result of decreased bone quantity and quality. World Health Organization (WHO) defines osteoporosis as a bone metabolic disease that often occurs, characterized by decreased bone mass and changes in bone tissue microarchitecture due to increased bone fragility and tendency to experience fractures. $[1,2]$

The increasing incidence of osteoporosis makes osteoporosis as a global health issue.[3.4]
Based on an analysis of risk data for Osteoporosis in the Indonesian Ministry of Health's Nutrition Research and Development Center, the prevalence of osteoporosis in Indonesia reaches $41.75 \%$ It shows that 2 out of 5 Indonesians are at risk for osteoporosis, and this figure is higher than the global prevalence of which only 1 in 3 is at risk of osteoporosis.[5,6,7] WHO defines osteoporosis based on bone mineral density (BMD).

There are 4 categories of bone density diagnosis based on T-scores $[6,8,9,10]$ :

1. Normal: T-score is greater than or equal to $-1 \mathrm{SD}$.

2. Osteopenia (low bone mass): T-score between -1 CRJIM • Vol 01・ Number 1・ May 2020 
SD to -2.5 SD.

3. Osteoporosis: T-score below -2.5 SD.

4. Advanced osteoporosis: T-score below -2.5 SD in the presence of one or more osteoporotic fractures.

Cancer patients are one part of the increase in patients newly diagnosed with osteoporosis. Postmenopausal breast carcinoma patients have a high risk of osteoporosis. It was caused by breast carcinoma, side effects of anti-cancer therapy, and post menopause.[11]

A bone microenvironment is a good place for the growth of malignant cells originating from distant tumors (metastases). In 1879, Stephan Paget mentioned that carcinoma cells had an increased migration and spread to the bone. Bone metastases are usually classified into osteolytic, osteoblastic/osteosclerotic, or mixed types. In breast carcinoma, the type of metastasis is a mixedtype.

The effects of chemotherapy cause $60-65 \%$ of women who get the CMF (Cyclophosphamidemethotrexate-5 fluorouracil) regimen and 50\% with the FAC (5-Fluorouracil-doxorubicin Cyclophosphamide) regimen to ovarian damage. Permanent ovarian damage is obtained by chemotherapy using cyclophosphamide, chlorambucil, and mitomycin C. [12,13,14]

Hormonal therapy using tamoxifen is associated with bone loss through its anti-selective estrogen receptor modulator (SERM) effects that are agonist and antagonistic to estrogen receptors. Besides Tamoxifen, aromatase inhibitors (AI) are also used in breast carcinoma. Aromatase inhibitors (AI) are responsible for the aromatization of androgens into estrogens in peripheral tissues. AI causes bone loss faster and heavier than normal processes in postmenopausal women. [15]

The other causes of osteoporosis are the use of glucocorticoids. It was often used as analgesics, palliative agents, antiemetics, or as part of therapy. Glucocorticoids initially increase bone resorption, then suppress osteoblast activity and eventually suppress bone formation.

\section{E T HOD S}

\section{Patient and Method}

Thirty female breast carcinoma patients with positive ER and HER2 negative who have undergone outpatient chemotherapy and hormonal therapy in the haematology department of Internal
Medicine, Saiful Anwar Hospital Malang, and 30 women without breast carcinoma as controls were included in this study.

The research design used was case-control study. All participants conducted BMD examination with a DEXA device, then measured the bone mineral density values.

\section{Statistical analysis}

Data is presented in mean and standard deviation. Unpaired categorical comparative data were analyzed by a Chi-square test (normal data distribution) and Mann Whitney (abnormal data distribution), the p-value was considered significant if $\mathrm{p}<0.05$. Bivariate analysis with Chi-square test that produces OR is used to determined effects of chemotherapy and hormonal therapy on BMD changes. All technical data processing results were analyzed by computerization using Statistical Product and Service Solution software, IBM SPSS Statistics 20 with a significance level of 0.05 ( $p=$ $0.05)$ and a confidence level of $95 \%(\alpha=0.05)$.

\section{RE S U L T S}

In this study there were 30 female patients with breast carcinoma who had undergone chemotherapy and hormonal therapy with tamoxifen, and 30 women without breast carcinoma as controls.

Table 1. Baseline Characteristics of participants

\begin{tabular}{lccc}
\hline \multirow{2}{*}{ Variables } & \multicolumn{2}{c}{ Group } & $\begin{array}{c}\text { p- } \\
\text { value }\end{array}$ \\
\cline { 2 - 3 } Age & $49.33 \pm 3.76$ & $\begin{array}{c}\text { Breast Ca } \\
\text { Patients }\end{array}$ & 0.625 \\
Height & $156.77 \pm 4.04$ & $153.97 \pm 3.78$ & 0.009 \\
Weight & $59.37 \pm 9.36$ & $59.90 \pm 12.49$ & 0.852 \\
BMI & $24.14 \pm 3.64$ & $25.19 \pm 4.94$ & 0.352 \\
BMI (n \%) & $2(3.3 \%)$ & $2(3.3 \%)$ & 0.312 \\
- Under & $17(28.3 \%)$ & $10(16.7 \%)$ & \\
- Normal & $9(15 \%)$ & $14(23.3 \%)$ & \\
- Over & $2(3.3 \%)$ & $4(6.7 \%)$ & \\
- Obesity & & & $<$ \\
Menopause & $18(36 \%)$ & $0(0 \%)$ & 0.001 \\
- no & $12(14 \%)$ & $32(50 \%)$ & \\
- yes & & & \\
Calcium intake & $15(25 \%)$ & $17(28.3 \%)$ & 0.605 \\
- no & $15(25 \%)$ & $13(21.7 \%)$ & \\
- yes & & & \\
\hline Data presented as mean \pm SD, or number $(\%)$ &
\end{tabular}

The age range of the control group and the sample that participated in this study were 30 to 60 years with an average of $49.87 \pm 4.59$ years (patients) and $49.33 \pm 3.76$ years (controls). The mean BMI values were $24.14 \pm 3.64 \mathrm{~kg} / \mathrm{m}^{2}$ (patients) and $25.19 \pm 4.94 \mathrm{~kg} / \mathrm{m}^{2}$. Overall, breast carcinoma patients included in the sample experienced menopause, and from the control 
group, there were 12 people (14\%) who had menopause (Table 1).

The chemotherapy used was FAC (fluorouracil-doxorubicin-cyclophosphamide) of 18 patients and 12 patients with paxusdoxorubicin. All of them use tamoxifen hormonal therapy.

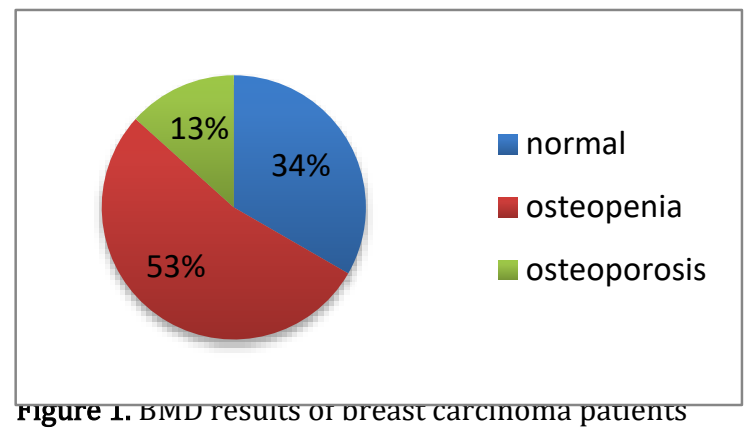

(Figure 1) shows breast carcinoma patients who have a normal BMD value of 34\%, 53\% included in the osteopenia category, and 13\% included osteoporosis. Osteoporosis examination sites were found in the femoral neck of 1 patient and 3 patients in the lumbar (L1-L4).

Table 2. Comparison of BMD values of breast carcinoma patients who have undergone chemotherapy and hormonal treatment compared with controls

\begin{tabular}{|c|c|c|c|}
\hline \multirow[b]{2}{*}{ Variable } & \multicolumn{2}{|c|}{$\operatorname{BMD}\left(\mathrm{g} / \mathrm{cm}^{2}\right)$} & \multirow[b]{2}{*}{ p-value } \\
\hline & $\begin{array}{l}\text { Breast } \\
\text { cancer }\end{array}$ & Control & \\
\hline Femoral neck & $0.72 \pm 0.11$ & $\begin{array}{c}0.69 \pm \\
0.09\end{array}$ & 0.727 \\
\hline Ward & $0.54 \pm 0.15$ & $\begin{array}{c}0.47 \pm \\
0.13\end{array}$ & 0.408 \\
\hline $\begin{array}{l}\text { Great } \\
\text { trochanter }\end{array}$ & $0.62 \pm 0.11$ & $\begin{array}{c}0.57 \pm \\
0.88\end{array}$ & 0.540 \\
\hline L1 & $0.76 \pm 0.16$ & $\begin{array}{c}0.67 \pm \\
0.13\end{array}$ & 0.158 \\
\hline L2 & $0.82 \pm 0.16$ & $\begin{array}{c}0.81 \pm \\
0.12\end{array}$ & 0.684 \\
\hline L3 & $0.87 \pm 0.16$ & $\begin{array}{c}0.87 \pm \\
0.15\end{array}$ & 0.529 \\
\hline L4 & $0.80 \pm 0.15$ & $\begin{array}{c}0.85 \pm \\
0.12\end{array}$ & 0.228 \\
\hline L1-L4 & $0.81 \pm 0.14$ & $\begin{array}{c}0.82 \pm \\
0.12\end{array}$ & 0.888 \\
\hline
\end{tabular}

Based on (Table 2), BMD values of the femoral neck, ward, great trochanter, L1, L2, L3, L4, and total L1-L4 in the examination of bone mineral density obtained $p$-value $>0.05$. It shows no significant difference between bone mineral density values in the femoral neck, ward, great trochanter, L1, L2, L3, L4, and L1-L4 of breast carcinoma patients who had undergone chemotherapy and hormonal treatment compared with controls.

Table 3. Comparison of T-score of breast carcinoma patients who have undergone chemotherapy and hormonal treatment compared with controls

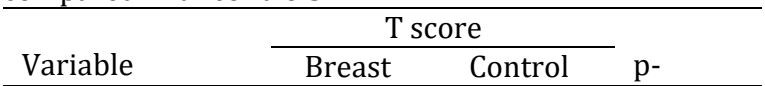

\begin{tabular}{lccc} 
& & & \\
\cline { 2 - 3 } Femoral neck & $-0.99 \pm$ & $-1.22 \pm$ & 0.517 \\
& 0.99 & 0.69 & \\
Ward & $-1.44 \pm$ & $-1.88 \pm$ & 0.860 \\
& 0.97 & 0.87 & \\
Great & $-0.80 \pm$ & $-1.42 \pm$ & 0.020 \\
trochanter & 1.16 & 0.77 & \\
L1 & $-1.30 \pm$ & $-1.58 \pm$ & 0.155 \\
& 1.33 & 1.13 & \\
L2 & $-0.93 \pm$ & $-1.69 \pm$ & 0.620 \\
& 1.39 & 1.13 & \\
L3 & $-0.55 \pm$ & $-0.51 \pm$ & 0.807 \\
& 1.39 & 1.22 & \\
L4 & $-1.69 \pm$ & $-1.45 \pm$ & 0.267 \\
& 1.13 & 0.89 \\
L1-L4 & $-1.15 \pm$ & $-1.09 \pm$ & 0.959 \\
& 1.13 & 0.94 & \\
\hline Data presented as mean \pm SD. Independent $t$-test.
\end{tabular}

Based on (Table 3), the value of T-score great trochanter, obtained p-value $0.02 \quad(<0.05)$. It indicates that there is a significant difference in bone mineral density values in the great trochanter of breast carcinoma patients who had undergone chemotherapy and hormonal treatment compared with controls, but not obtained Significant differences in other locations.

Table 4. Effects of chemotherapy and hormonal therapy on bone mineral density

\begin{tabular}{lcccc}
\hline & $\begin{array}{l}\text { Low } \\
\text { BMD, } \\
\mathrm{n}(\%)\end{array}$ & $\begin{array}{c}\text { Normal } \\
\text { BMD, } \\
\mathrm{n}(\%)\end{array}$ & $\begin{array}{c}\mathrm{p}- \\
\text { value }\end{array}$ & $\begin{array}{c}\text { OR } \\
(95 \% \\
\mathrm{CI})\end{array}$ \\
\hline Breast & 13 & 17 & 0.008 & 0.233 \\
cancer & $(21.7)$ & $(28.3)$ & & $(0.077-$ \\
& & & & $0.708)$ \\
Control & 23 & $7(11.7)$ & & \\
& $(38.3)$ & & & \\
\hline Total & 36 & $24(40)$ & & \\
\multicolumn{7}{l}{ Chi-square test } \\
\multicolumn{6}{l}{ (60) }
\end{tabular}

(Table 4) shows the results of the Odds Ratio (OR) of 0.233 with a $p$-value of 0.008 which shows that in breast carcinoma patients who have undergone chemotherapy and hormonal therapy the incidence rate is significantly lower by 0.233 times compared to normal controls.

\section{I S C U S S I O N}

This study aims to determine the effect of chemotherapy and hormonal therapy on breast carcinoma on bone mineral density in evaluating the possibility of decreasing bone mineral density (in this case osteoporosis) in breast carcinoma patients with ER + and HER2-. The number of samples collected from the August-September 2015 period were 30 female patients with breast carcinoma in poly haematology oncology of dr. Saiful Anwar, General Hospital, Malang who had undergone 
chemotherapy and hormonal therapy and 30 people without breast carcinoma as controls. All included in this study were those that met the study inclusion criteria, and those who were not included in the inclusion criteria were immediately excluded as the study sample.

The age range of the control group and the sample that participated in this study were 30 to 60 years with an average of $49.87 \pm 4.59$ years (patients) and $49.33 \pm 3.76$ years (controls). The mean BMI values were $24.14 \pm 3.64 \mathrm{~kg} / \mathrm{m} 2$ (patient) and $25.19 \pm 4.94 \mathrm{~kg} / \mathrm{m} 2$ (Table 1).

Description of bone mineral density in breast carcinoma samples with hormonal therapy is $34 \%$ with normal BMD values, $53 \%$ osteopenia and $13 \%$ including osteoporosis, with osteoporosis locations found in the femoral neck of 1 patient and 3 patients in lumbar (L1-L4). The Spanik and Spanikova studies (with 8 times the number of study samples) have the same percentage of BMD osteopenia and osteoporosis, which is $43.35 \%$ with the most osteoporosis locations in the lumbar. Therapy of breast carcinoma causes bone loss as much as $2-20 \%$ annually. Loss of BMD during carcinoma therapy generally occurs more rapidly in the trabecular bone in the lumbar vertebra than in the cortical bone in the thigh (femur).[11,16,17]

In this study, breast carcinoma patients who received FAC chemotherapy were 18 patients and 12 patients with Paxus-doxorubicin, and all breast carcinoma patients received tamoxifen hormone therapy. Different types of breast carcinoma require different therapies and management. In breast carcinomas with oestrogen receptor positive, one part of the treatment includes ways to reduce oestrogen levels temporarily or permanently to prevent further carcinoma stimulation. Management of breast carcinoma (surgery, chemotherapy and hormonal therapy) is known to cause amenorrhea or early menopause.16,18 Drugs used in chemotherapy can cause permanent or temporary ovarian dysfunction. Chemotherapy related amenorrhea (CRA) based on the American College of Obstetricians and Gynaecologists is defined as the cessation of menstruation for 6 months. Other literature defines cessation of menstruation for at least 3 months during or immediately after administration of adjuvant chemotherapy, cessation of menstruation 6,8 , or 12 months, or cessation of menstruation during chemotherapy and no further menstruation. $[13,17,19,20,21]$

Chemotherapy can cause ovarian atrophy and loss of primordial follicles, and damage to ovarian pregranulosa cells due to injury to blood vessels and focal fibrosis of the ovarian cortex caused by exposure to chemotherapy. Follicular damage due to chemotherapy may cause permanent menstruation, temporary amenorrhea, irregular menstruation (perimenopause), or complete ovarian failure (menopause). Although the mechanism is not fully understood, in vitro studies show that changes in apoptosis in pregranulosa cells result in direct destruction of the follicle. In short chemotherapy causes destruction of primordial follicles and decreased follicular maturation. $[19,20,22]$

(Table 3) shows no effect of hormone therapy given on bone mineral density in the femoral neck, ward, L1, L2, L3, L4, and L1-L4, this is seen with the presence of $p$-value $>0.05$ in the comparison of control and patient groups. However, in the great trochanter, a $p$-value of $0.02(<0.05)$ was obtained which showed that there was an effect of chemotherapy and hormonal therapy on bone mineral density. Odds Ratio (OR) 0.233 with $p$-value 0.008 in shows the protective effect of chemotherapy and hormonal therapy on breast carcinoma on decreasing bone mineral density. This is indeed contrary to previous studies. In a study conducted by Hadji (2009) and Giuse (2006) states that the provision of hormonal therapy as a therapy for women with breast carcinoma showed a decrease in bone mineral density and increased risk of fractures. However, in a study conducted by Chandra (2012) regarding the singh index accuracy compared to DEXA in the examination of osteoporosis in patients with breast carcinoma, it was stated that there was no relationship between hormonal therapy and decreased bone mineral density. [20,23,24]

The study of Spanik and Spanikova (2010), Body (2010), Hadji et al. (2012), and Inoue et al. (2015) showed a rapid decrease in bone mineral density in the first 1-3 years of hormonal therapy. BMD decreases in the range of 0.5 - 4\% per year. And after that the decrease in BMD will run more slowly. The rapid decline at the start of hormonal therapy is thought to be due to a rapid decrease in oestrogen levels in the premenopausal stage to the menopause stage. After the initiation of hormonal therapy in 
breast carcinoma, a rapid decline in oestrogen occurs within 3 weeks and causes a rapid and significant loss of bone mass. This happens because oestrogen indirectly regulates bone resorption activity by osteoclasts, where a decrease in oestrogen levels will increase the amount of bone resorption. After menopause, low residual oestrogen levels are known to be important for maintaining bone density, and carcinoma therapy that decreases oestrogen can have a negative effect on bone. $[11,16,17,25,26]$

The protective effect of hormonal therapy seen in table 14 can be caused by the use of tamoxifen as a hormonal therapy. Tamoxifen is said to be more a Selective Oestrogen Receptor Modulator (SERM) than an antioestrogen. SERMs are structurally divided into groups that bind both ER $\alpha$ and ER $\beta$ and produce oestrogen agonist effects in some tissues, but have oestrogen antagonistic activity in other tissues. ER $\alpha$ is expressed in osteoblasts and osteoclasts, and ER $\beta$ is expressed in osteoblasts, showing a direct effect of oestrogen on bone metabolism. Tamoxifen as a SERM in breast carcinoma has anti-tumor effects including its ability as an antagonist to oestrogen proliferation through competitive binding to oestrogen receptors. In contrast tamoxifen has agonist activity in the spine, uterus and some cardiovascular risk markers. The pharmacology of SERM can be explained through interactive mechanisms: differences in ER expression in target tissues, differences in ER conformation in ligand bonds, and differences in expression and bonds in oestrogen coregulator proteins.[27,28] In breast carcinoma, tamoxifen competitively binds to oestrogen receptors and works as an anti-proliferative in breast epithelium. Tamoxifen also has estrogen-like effects on bones and maintains bone mineral density. ${ }^{[29]}$ In the COBRA (Consortium on Breast Cancer Pharmacogenomics) study, tamoxifen caused a greater increase in BMD of breast carcinoma patients undergoing chemotherapy than those without. This increase in BMD may be due to chemotherapy affecting changes in bone metabolism and ovarian function that cause additional effects of oestrogen on the bones. Tamoxifen increases BMD in Lumbar in postmenopausal women as in women with breast carcinoma by decreasing bone turnover. A significant increase in BMD is found in the lumbar which is a trabecular bone and not at the tip of the femur which is predominantly cortical bone.[30]

This study has various limitations. Some things that need attention are the limitations in this study, among others: more number of research samples needed to better be able to see the relationship of the effects of hormonal therapy on bone mineral density, duration of hormonal therapy administration, nutrition (actual calcium intake) and physical activity were not evaluated thus affecting the bone mass density of the sample, and the need for a density examination before the treatment of breast carcinoma (baseline BMD) and during therapy to evaluate the bone mineral density.

In conclusion, that chemotherapy and hormonal therapy have a protective effect on the bone mineral density of breast carcinoma patients in Saiful Anwar Hospital, Malang.

\section{R E F E R E N C E S}

1. Clifford R. Osteoporosis. Goldman's Cecil Medicine; twenty-fourth edition. 2013; 1577-1587. [https://doi.org/10.1016/C2009-0-42832-0]

2. World Health Organization Regional Office for Europe. What Evidence is there for the Prevention and Screening of Osteoporosis? 2009.

3. Guglielmi G, Muscarella S, Bazzocchi A. Integrated Imaging Approach to Osteoporosis: State-of-the-Art Review and Update. RSNA. 2011; 1343-1364. [doi: 10.1148/rg.315105712]

4. Julia O, Totosy de Zepetnek, Giangregorio LM, Craven C. Whole-Body Vibration as Potential Intervention for People with Low Bone Mineral Density and Osteoporosis: a Review. Journal of Rehabilitation research and development. 2009; 4(46): 529-542. [DOI:10.1682/JRRD.2008.09.0136]

5. Tori H. Osteoporosis. Textbook of Natural Medicine Fourth Edition. Elsevier Inc. 2013; 194:1662-1677.

6. Cosman F, Lindsay R, LeBoff MS, de Beur, Tanner B. Clinician's Guide to Prevention and Treatment of Osteoporosis. National Osteoporosis Foundation. 2014. [doi: 10.1007/s00198-014-2794-2]

7. Depkes. Pedoman Pengendalian Osteoporosis. Jakarta. 2008.

8. Advances in Osteoporosis: Better Identification of Risk Factors can Reduce Morbidity and Mortality. J. Internal Med. 1996. 239(4): 299-304 [https://doi.org/10.1046/j.13652796.1996.429781000.x ]

9. Kawiyana I Ketut S. Osteoporosis Patogenesis Diagnosis dan Penanganan Terkini. J Peny Dalam. 2009; 5(10):157168.

10. World Health Organization. The Assessment of Osteoporosis at Primary Health Care Level. 2004

11. Spanik S, Spanikova S. Bone Mineral Density in Early Breast Cancer Patients. Bratisl Lek Listy. 2010; 111(1):2732.

12. Rizzoli R, Body J, Brandi ML, Cannata-Andia J, Chappard D, El Maghraoui, Glüer C, et al. Cancer-Associated Bone Disease. International Osteoporosis Foundation and National Osteoporosis Foundation. 2013. [doi: 10.1007/s00198-013-2530-3] 
13. National Osteoporosis Society. Breast Cancer Treatments and Osteoporosis. 2008.[doi: $10.1159 / 000368843$ ]

14. Reid DM, Doughty J. Guidance for the Management of Breast Cancer Treatment Induced Bone Loss: a Consensus Position Statement from a UK Expert Group. Cancer Treat Rev. Elsevier Ltd. UK. 2008;34:S1-S18. [doi: 10.1016/i.jbo.2017.03.001]

15. Body J. Prevention and Treatment of Side-Effects of Systemic Treatment: Bone Loss. Annals of Oncology. 2001; 21( 7): vii180-vii185.

16. Hadji P, Gnant M, Body J, Bundred NJ, Brufsky M, Coleman $\mathrm{RE}$, Guise TA, et al. Cancer Treatment-Induced Bone Loss in Premenopausal Women: a Need for Therapeutic Intervention? Cancer Treatment Reviews. 2012; (38); 798-806.

17. Raisz G. Pathogenesis of Osteoporosis: Concepts, Conflicts, and Prospects. J. Clin. Invest. 2005;115:33183325. [doi: 10.1172/JCI27071]

18. Berliere M, Duhoux F, Galant C, Dalenc F, Baurain JF, Leconte I, et al. Chemotherapy-Related Amenorrhea in Breast Cancer: Review of the Main Published Studies, Biomarkers of Ovarian Function and Mechanisms Involved in Ovarian Toxicity. 2011. Available from: http://www.intechopen.com/books/amenorrhea/chem otherapy-related-amenorrhea-in-breast-cancer-reviewofthe-main-published-studies-biomarkers-of

19. Hadji P. Aromatase Inhibitor-Associated Bone Loss in Breast Cancer Patients is Distinct from Postmenopausal Osteoporosis. Critical Reviews in Oncology/Hematology. 2009; (69): 73-82.

20. Shuster LT, Rhodes DJ, Gostout BS, Grossardt BR, and Roccae WA. Premature Menopause or Early Menopause: long-term health consequences. Maturitas, 2010; 65(2): 161.

21. North American Menopause Society. Management of Osteoporosis in Postmenopausal Women: 2010 position statement of The North American Menopause Society. Menopause: The Journal of The North American Menopause Society. 2010; 17(1): 23-54. [doi: 10.1097/gme.0b013e3181c617e6.]

22. Murthy V, Chamberlain NS. Menopausal Symptoms in Young Survivors of Breast Cancer: A Growing Problem Without an Ideal Solution. Cancer Control. 2012;10(19): 317-329.

23. Chandra L. Akurasi Indeks Singh dibandingkan Dual Energy X-Ray Absorptiometry (DEXA) dalam Evaluasi Osteoporosis (Studi Kasus pada Pasien Karsinoma Payudara dengan Reseptor Estrogen Positif). 2013.

24. Inoue $H$, Hirano A, Ogura $K$, Hattori A, Kamimura $M$, Okubo F, et al. The Effect of Anastrozole on Bone Mineral Density during the First 5 Years of Adjuvant Treatment in Postmenopausal Women with Early Breast Cancer. Springer Plus. 2015; 4:303-7. [DOI: 10.1186/s40064-015-1096-2]

25. Guise TA. Bone Loss and Fracture Risk Associated with Cancer Therapy. The Oncologist. 2006;11:1121-1131. [DOI: 10.1158/1078-0432.ccr-10-1595]

26. Lee W, Cheng H, Chao H, Wang P. The Role Of Selective Estrogen Receptor Modulators On Breast Cancer: from Tamoxifen to Raloxifene. Taiwan J Obstet Gynecol, 2008; 3(47); 24-31. [https://doi.org/10.1016/S10284559(08)60051-0]

27. Goldstein SR, Siddhanti S, Ciaccia AV, Plouffer L. A Pharmacological Review of Selective Oestrogen Receptor Modulators. Human Reproduction Update. 2000; 6(3): 213-234.

\section{Cite this as:}

Nurshanty A, Wardhani SO, Suryana BPP. Effect of Chemotherapy and Hormonal Therapy on Bone Mineral Density in Patients with Breast Cancer in dr. Saiful Anwar Hospital Malang. Clinical and Research Journal in Internal Medicine, 1.1 (2020): 25-32. 